\title{
Role of Oral Rabies Vaccines in the Elimination of Dog-Mediated Human Rabies Deaths
}

Ryan M. Wallace, Florence Cliquet, Christine Fehlner-Gardiner, Anthony R. Fooks, Claude T. Sabeta, Alvaro Aguilar Setién, Changchun Tu, Vlad Vuta, Boris Yakobson, Dong-Kun Yang, Gideon Brückner, Conrad M. Freuling, Lea Knopf, Artem Metlin, Patricia Pozzetti, Pebi Purwo Suseno, Sean V. Shadomy, Gregorio Torres, Marco Antonio Natal Vigilato, Bernadette Abela-Ridder, Thomas Müller

Domestic dogs are responsible for nearly all the $\approx 59,000$ global human rabies deaths that occur annually. Numerous control measures have been successful at eliminating dog-mediated human rabies deaths in upper-income countries, including dog population management, parenteral dog vaccination programs, access to human rabies vaccines, and education programs for bite prevention and wound treatment. Implementing these techniques in resource-poor settings can be challenging; perhaps the greatest challenge is maintaining adequate herd immunity in free-roaming dog populations. Oral rabies vaccines have been a cornerstone in rabies virus elimination from wildlife populations; however, oral vaccines have never been effectively used to control dog-mediated rabies. Here, we convey the perspectives of the World Organisation for Animal Health Rabies Reference Laboratory Directors, the World Organisation for Animal Health expert committee on dog rabies control, and World Health Organization regarding the role of oral vaccines for dogs. We also issue recommendations for overcoming hesitations to expedited field use of appropriate oral vaccines.

Since the advent of Pasteur's germ theory and the general acceptance that infectious diseases do not develop spontaneously, humankind has strived to

Author affiliations: Centers for Disease Control and Prevention, Atlanta, Georgia, USA (R.M. Wallace, S.V. Shadomy); Agency for Food, Environmental, and Occupational Health and Safety, Malzéville, France (F. Cliquet); Canadian Food Inspection Agency, Ottawa, Ontario, Canada (C. Fehlner-Gardiner); Animal and Plant Health Agency, Weybridge, UK (A.R. Fooks); Onderstepoort Veterinary Institute, Pretoria, South Africa (C.T. Sabeta); Unidad de Investigación Médica en Inmunología, Coordinación de Investigación en Salud, Instituto Mexicano del Seguro Social (IMSS), Mexico City, Mexico (A.A. Setién); Academy of Agricultural Sciences, Changchun, China (C. Tu); Institute for Diagnosis and Animal Health, Faculty of Veterinary Medicine, Bucharest, Romania (V. Vuta); Kimron Veterinary Institute, Beit Dagan, reduce and eliminate pathogens that pose a serious public health threat. Incorporating routine vaccinations to control human diseases such as pneumonia, diarrhea, pertussis, measles, and polio contributed to the prevention of $>10$ million human deaths during 2010-2015 (1). Intensive global efforts toward disease eradication have focused on only a few diseases, including Guinea worm disease (dracunculiasis) (>99\% reduction in human cases), smallpox (eradicated in 1980), rinderpest (eradicated in 2011), polio ( $99 \%$ reduction in human cases), and lymphatic filariasis (73\% reduction in human cases) (2-6). Those disease eradication efforts have focused on pathogens that are host-restricted or affect only a single host. In 2015, the world called for action by setting a goal of zero human dog-mediated rabies deaths by 2030 worldwide. In 2018, the World Health Organization (WHO), the World Organisation for Animal Health (OIE), the Food and Agriculture Organization of the United Nations, and the Global Alliance for Rabies Control launched the Global Strategic Plan for global elimination of dog-mediated human rabies deaths by 2030, which represents the first major effort to eliminate a classical zoonosis and poses

Israel (B. Yakobson); Animal and Plant Quarantine Agency, Gimcheong-si, South Korea (D.-K. Yang); World Organisation for Animal Health, Paris, France (G. Brückner, P. Pozzetti, G. Torres); Friedrich-Loeffler-Institut, Greifswald-Insel Riems, Germany (C.M. Freuling, T. Müller); World Health Organization, Geneva, Switzerland (L. Knopf, B. Abela-Ridder); Federal Centre for Animal Health, Vladimir, Russia (A. Metlin); Ministry of Agriculture, Jakarta, Indonesia (P. Purwo Suseno); Food and Agriculture Organization of the United Nations, Rome, Italy (S.V. Shadomy); Pan American Health Organization, Rio de Janeiro, Brazil (M.A.N. Vigilato)

DOI: https://doi.org/10.3201/eid2612.201266 
unique challenges not encountered during prior disease elimination efforts (7-9).

Among the various rabies reservoir species $(10,11)$, domestic dogs pose the greatest threat to global public health $(12,13)$. Dog-mediated rabies is responsible for an estimated 59,000 human deaths annually $(95 \%$ CI 25,000-159,000) (14). Despite the complexities inherent in controlling zoonotic diseases, historical experience has shown that dog-mediated rabies virus elimination is feasible and cost-effective (15). Dog-mediated rabies has been eliminated from nearly every high-income country through the implementation of dog vaccination and population management programs $(16,17)$. Dog rabies control efforts in low- and middle-income countries are estimated to prevent 2.9 million human rabies deaths annually; however, recent examples of successful, large-scale dog rabies elimination in low- and middle-income countries are rare and largely limited to Latin America $(14,18-22)$. In recent decades, vaccination efforts have stagnated in many countries because of scarce funding for animal health sector elimination initiatives and perceived barriers to effectively vaccinating high-risk dog populations $(8,23)$.

A great paradox exists in the field of global rabies elimination: oral rabies vaccination (ORV) is the main component of elimination of rabies from wildlife populations, which cause only modest human deaths (24-27), whereas ORV is not used to complement parenteral vaccination for elimination of rabies in dog populations (28), which are responsible for more human deaths than any other single zoonotic pathogen. At present, parenteral vaccination is the only approach used for addressing dog-mediated rabies at-scale, despite frequent publications and field reports of the inadequacies of this approach among important subpopulations of susceptible dogs (Table 1) (39).

\section{Rationale for the Consideration of Oral Vaccines for Dog Vaccination Campaigns}

Elimination of dog-mediated rabies from high-income countries was achieved through parenteral vaccination of dogs at fixed locations (e.g., veterinary clinics and fixed community vaccination posts) and has been associated with higher levels of logistical, political, and economic development. In many rabies-endemic countries, the logistical infrastructure is inadequate to support vaccination campaigns capable of reaching adequate herd immunity (estimated at 70\%) (8). Alternative vaccination methods that overcome these infrastructure deficits, such as capture-vaccinate-release (CVR) and door-to-door vaccination, have been piloted in subnational settings and have shown to be highly effective (40-43). However, the feasibility of scaling up campaigns that rely upon parenterally focused alternative vaccination methods is now in doubt $(44,42)$. Parenteral vaccination by CVR techniques has led to tangible reductions in dog-mediated human rabies deaths in areas such as Bali, Indonesia, and Goa, India. However, these programs are relatively small in scale (vaccinating $<100,000$ dogs per campaign-year). To date, no example of a large-scale, national campaign that relies primarily on the laborintensive method of CVR exists. The sheer number of vaccinators required to enact the CVR technique at-scale requires a labor pool that does not yet exist in many endemic countries $(8,44)$. A cadre of an estimated 1.1 million vaccinators would be needed to conduct a national CVR campaign in India (42).

In contrast, ORV targets similar dog populations as CVR (i.e., free-roaming) but requires substantially less labor and expertise. Recent studies conducted in Asia and the Americas have shown that although CVR techniques applied to inaccessible dog populations are inefficient (reaching only 10-20 dogs per vaccinator per day), vaccinators using ORV in these same dog populations can far exceed 50 successful vaccinations each day $(42,45,46)$. In settings where alternative vaccination methods are necessary to reach adequate herd immunity, scalability will likely require inclusion of ORV to effectively eliminate dog-mediated rabies.

Although infrastructure is an important component of rabies vaccination, a profusion of other considerations also influence the feasibility of an approach that will be most successful. Whether a population of dogs are accessible for parenteral vaccination depends on cultural, environmental, and economic factors. In most rabies ontrol programs, a positive association exists between dog accessibility and efficiency of vaccinations

\begin{tabular}{|c|c|c|c|c|c|}
\hline \multicolumn{3}{|c|}{ Successful vaccination programs } & \multicolumn{3}{|c|}{ Unsuccessful vaccination programs } \\
\hline Country & Vaccination coverage, $\%$ & Reference & Country & Vaccination coverage, $\%$ & Reference \\
\hline Zambia & 80 & $(29)$ & Chad & 19 & $(30)$ \\
\hline Mexico & $>90$ & (31) & Chad & 24 & (32) \\
\hline Chad & 74 & (30) & Kenya & 29 & (33) \\
\hline Thailand & 70 & (34) & Nigeria & 17 & (35) \\
\hline Bolivia & 85 & (36) & South Africa & 56 & (37) \\
\hline Tanzania & 68 & $(38)$ & Tanzania & 9 & (38) \\
\hline
\end{tabular}


delivered, as well as cost-effectiveness, predicated on parenteral vaccination. With ORV, this fundamental relationship can change (46). Several studies have shown that in areas with low dog accessibility, parenteral vaccination was either ineffective or inefficient, but ORV was able to achieve adequate coverage while remaining a cost-effective public health intervention (42,45-48). Although ORV has been used for $>40$ years in highincome countries to successfully control and eliminate rabies in wildlife $(24,27)$, hesitancy to implement ORV as a component of mass dog vaccination campaigns has resulted in a dearth of evidence to argue for the integration, impact, and cost of these vaccines in the context of dog rabies control.

\section{Factors Contributing to Underutilization of Oral Rabies Vaccines in Dog Vaccination Programs}

Decades of debate over the potential role of ORV for dogs has left a confusing landscape of guidance and perspectives (49-53). Here, we discuss the greatest deterrents to the inclusion of ORV in routine dog vaccination programs and how to encourage their safe and cost-effective use.

\section{Safety of Oral Rabies Vaccines}

Unintended and long-lasting impacts on humans, as seen with the large-scale field use of oral vaccines for poliovirus and smallpox virus $(54,55)$, have not been observed with oral rabies virus vaccines $(56,57)$. Only very few sporadic adverse events in animals or humans, without any epidemiologic impact, have been reported when baits were distributed randomly in the environment (56-63). Given the close proximity of free-roaming dogs to humans, particularly in urban environments, distributing vaccines through a hand-out model would effectively reduce unintended exposures to vaccine virus compared with environmental distribution of baits (Figures 1, 2).

Thorough safety evaluations are essential before any consideration of field distribution of oral rabies vaccines, including safety for target and major nontarget species, virus dissemination potential, genetic stability, environmental safety, and mode of distribution (Table 2). At least 5 guidelines have been developed to describe the process by which candidate oral vaccines should be evaluated for safety and efficacy (i.e., guidelines issued by OIE, WHO, the European Directorate for the Quality of Medicines, the US Food and Drug Administration, and the US Department of Agriculture Center for Veterinary Biologics) (49$52,64,65)$. These guidelines are highly technical and developed from a regulatory point of view. Publicly available and plain-language vaccine construct safety evaluations have been developed for some veterinary vaccines, such as those released by the European Medicines Agency (https://www.ema.europa.eu/ en/medicines/veterinary).

Evaluating of vaccine safety can be a complex and multifaceted process. A standardized safety assessment model was proposed in 2019 by Head et al. (66), which describes a method for evaluating the animal and human health impacts of specified vaccine constructs under any potential field-use setting. Increased use of such types of risk assessment tools and dissemination of plain-language safety evaluation results can provide a stronger argument for policy makers to justify the use of oral rabies vaccines.

To address unfounded concerns related to safety of oral rabies virus vaccines, a few actions are recommended. First, global health agencies should provide
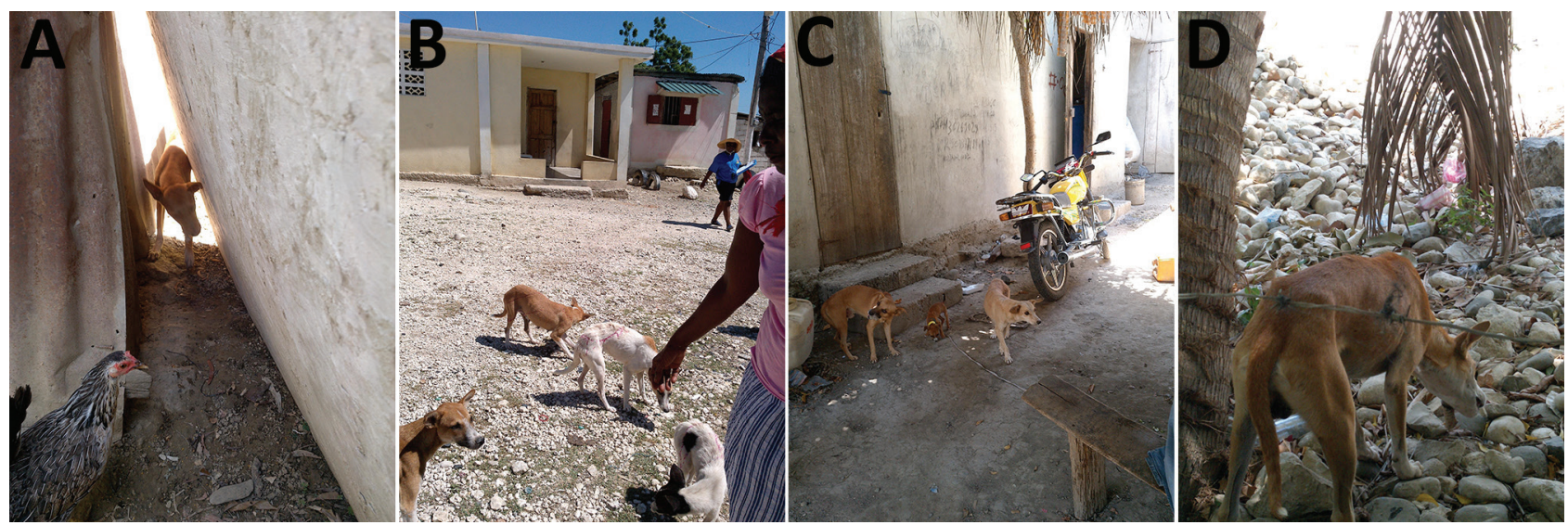

Figure 1. Oral rabies vaccines can be helpful in vaccinating dog populations where traditional parenteral methods have failed to reach adequate vaccination coverages, Haiti. A) A dog hiding behind 2 buildings is vaccinated with an oral rabies vaccine. B) A family with 4 free-roaming dogs watches as they ingest an oral rabies vaccine bait. C) Dogs can be protective of puppies, so oral rabies vaccines provide a safer method to vaccinators and reduce the risk of bites during parenteral vaccination. D) Fences and other barriers can make difficult tasks for parenteral vaccinators. A dog is vaccinated through a barbed wire fence with an oral rabies vaccine. 


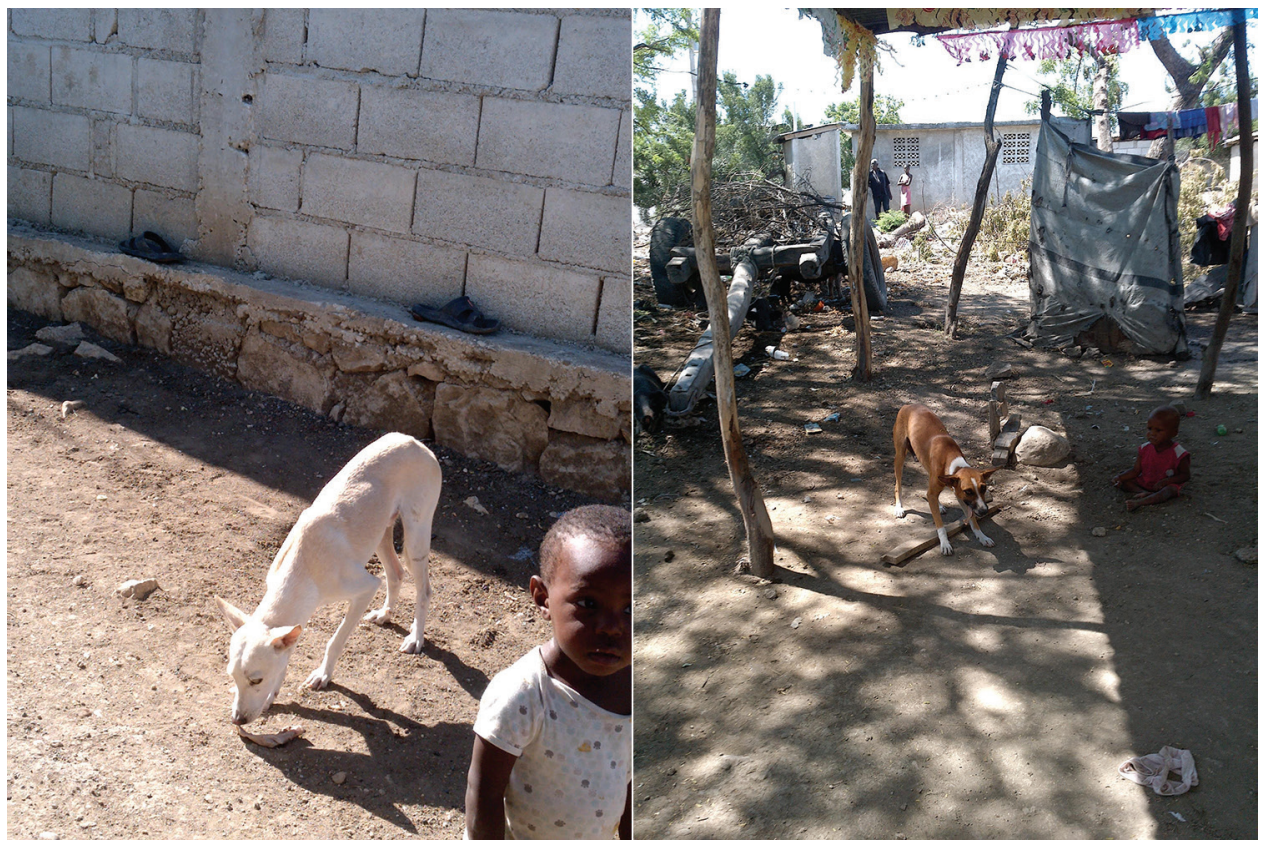

Figure 2. Dogs receiving oral rabies vaccines have the potential to expose community members, particularly children, Haiti. Oral rabies vaccines must be safe for dogs as well as the humans and animals that live near dogs. Children particularly are at risk for exposure to oral rabies vaccines through bites and licks from recently vaccinated dogs or when vaccines are left in the community. The unintended contact with the vaccine can be effectively reduced when a hand-out model (removal of unconsumed or partly ingested baits) is used.

guidance on conducting hand-out oral vaccination programs for dogs. Second, global health agencies should provide guidance to policy makers on how to interpret complex safety evaluation studies. Finally, policy-makers should be encouraged to evaluate the animal and human health impacts (beneficial and harmful) from use of ORV as a complement to injectable vaccines in dog vaccination programs.

\section{Licensure of Oral Rabies Vaccines}

Licensure of veterinary products ensures that a national professional regulatory organization has deemed the product safe for the target animal, potential nontarget animals, and humans. Several oral rabies vaccine products are licensed for use in wildlife, yet licensure has not been obtained for these products for use in dogs despite ample studies establishing their safety and efficacy. Vaccine licensure is not a globally consistent process, and licensure in 1 country might not be recognized by others. Licensure, if provided by a highly recognized agency (e.g., US Food and Drug Administration or European Medicines Agency), should translate to wideranging use and acceptance of the product globally,

\begin{tabular}{ll}
\hline Table 2 & Summary of recommendations for the evaluation of oral rabies vaccines for vaccine candidates before use in the field \\
\hline No. & Major categories for assessment of an oral rabies vaccine candidate* \\
\hline 1 & Description of the manufacturer \\
\hline 2 & Description of the vaccine construct \\
\hline 3 & Is the vaccine safe for the target animal? \\
\hline 5 & Has safety been assessed for potential non-target animals? \\
\hline 6 & Has safety been assessed in nonhuman primates? \\
\hline 7 & Does the vaccine elicit an immune response in target animals? \\
\hline 9 & Have virulent challenge studies been conducted to assess duration of immunity? \\
\hline 10 & Does the vaccine replicate in host tissues and is replicating virus excreted from animals? \\
\hline 11 & Is the bait composition attractive to the target animal, and does it convey delivery of the vaccine to the target host-anatomy? \\
\hline 12 & Has the vaccine been evaluated under field conditions and are storage requirements known? \\
\hline 13 & Has an economic cost-benefit assessment been conducted? \\
\hline 14 & Is the product currently acknowledged by an international public health agency for field use? \\
\hline 15 & Is the product currently licensed in any countries for field use? \\
\hline 16 & Can the responsible authority conduct postvaccination monitoring for persons potentially exposed to the vaccine? \\
\hline 17 & $\begin{array}{l}\text { Can the responsible authority conduct postvaccination monitoring for vaccine exposures from contact with recently vaccinated } \\
\text { dogs? }\end{array}$ \\
\hline 18 & Is there an effective postexposure prophylaxis for humans exposed to the oral rabies vaccine? \\
\hline 19 & Can the responsible health authority provide postexposure prophylaxis for persons potentially exposed to the vaccine? \\
\hline${ }^{*}$ Adapted from World Health Organization 2007 recommendation on oral rabies vaccine assessment (51).
\end{tabular}


Table 3. Landscape analysis of potential oral rabies vaccine candidates

\begin{tabular}{|c|c|c|c|c|}
\hline Vaccine name & Manufacturer & Construct & Review status* & Licensure status \\
\hline V-RG & $\begin{array}{l}\text { Boehringer Ingelheim, } \\
\text { Germany }\end{array}$ & Recombinant vaccinia virus & Safe and efficacious & $\begin{array}{l}\text { Licensed for wildlife in } \\
\text { Europe and USA }\end{array}$ \\
\hline ONRAB & Artemis, Canada & Recombinant adenovirus & Safe and efficacious & $\begin{array}{l}\text { Licensed for wildlife in } \\
\text { Canada }\end{array}$ \\
\hline SPBN GASGAS & Ceva, France & Recombinant rabies virus & Safe and efficacious & $\begin{array}{l}\text { Licensed for wildlife in } \\
\text { Europe }\end{array}$ \\
\hline ERA G333 & Prokov, Russia & Recombinant rabies virus & Not assessed & $\begin{array}{c}\text { Licensed for wildlife in } \\
\text { Russia }\end{array}$ \\
\hline SAG2 & VIRBAC, France & Attenuated rabies virus & Safe and efficacious & $\begin{array}{l}\text { Licensed for wildlife in } \\
\text { Europe }\end{array}$ \\
\hline SAD B19 & Ceva, France & Attenuated rabies virus & Low residual pathogenicity & $\begin{array}{l}\text { Licensed for wildlife in } \\
\text { Europe }\end{array}$ \\
\hline SAD Bern & Bioveta, Czech Republic & Attenuated rabies virus & Low residual pathogenicity & $\begin{array}{l}\text { Licensed for wildlife in } \\
\text { Europe }\end{array}$ \\
\hline SAD Clone & Bioveta, Czech Republic & Attenuated rabies virus & Low residual pathogenicity & $\begin{array}{l}\text { Licensed for wildlife in } \\
\text { Europe }\end{array}$ \\
\hline RV-97 & FGBI ARRAIH, Russia & Attenuated rabies virus & Low residual pathogenicity & $\begin{array}{c}\text { Licensed for wildlife in } \\
\text { Russia }\end{array}$ \\
\hline KMIEV-94 & $\begin{array}{c}\text { Institute of Experimental } \\
\text { Veterinary, Belarus }\end{array}$ & Attenuated rabies virus & Not assessed & $\begin{array}{c}\text { Licensed for wildlife in } \\
\text { Belarus }\end{array}$ \\
\hline VRC-RZ2 & Kazakhstan & Attenuated rabies virus & Not assessed & $\begin{array}{c}\text { Licensed for wildlife in } \\
\text { Kazakhstan }\end{array}$ \\
\hline
\end{tabular}

because in-country licensure in each rabies-endemic country is neither scientifically necessary nor ethically justified, and therefore unrealistic.

Off-label use of vaccines commonly occurs, especially when broad support from national and international professional organizations (e.g., OIE, $\mathrm{WHO}$, veterinary associations) exists. OIE Reference Laboratories for Rabies, as part of their expertise duties, are available to assist OIE in such a prequalification review process. Only vaccines that have been licensed for wildlife in accordance with international recommendations $(49-52,64,65)$ and have shown the highest level of safety and efficacy (based on the provisions for licensing stipulated by OIE) should be considered for prequalification and off-label use in dogs (67) (Table 3). Benchmark immunogenicity studies and field trials related to bait acceptance should form the basis for either conditional or fullfledged licensure of oral rabies vaccines for dogs. Given the similar immunologic characteristics of dog populations across countries, results of immunogenicity studies conducted in one country should be considered valid in other countries.
To overcome barriers to licensure of oral rabies vaccines, several actions are recommended. First, although licensure can be a long, arduous, and expensive process, manufacturers should continue to seek central licensure for use of their products in dogs. Second, OIE should continue its efforts to promote the concept of vaccine regulatory convergence among OIE member countries. Third, although OIE and WHO recognize the need for use of animal vaccines off-label, a prospective approach to validating oral rabies vaccines, such as the WHO vaccine prequalification process, should be developed to provide more confidence in the use of oral rabies vaccines, both in field-trials and integration into mass parenteral vaccination programs. Fourth, prequalification should be a future requirement for any oral rabies vaccine to be used for dogs in projects funded or supervised by the United Against Rabies initiative, thereby creating an incentive for manufacturers to invest into this area. Finally, OIE and WHO should consider developing a global regulatory science agenda for oral rabies vaccines, similar to what is recommended for human vaccines.

\begin{tabular}{|c|c|c|c|c|}
\hline $\begin{array}{l}\text { Accessibility of the dog } \\
\text { population }\end{array}$ & Central point & Door-to-door & Capture-vaccinate-release & Oral vaccination \\
\hline Owned, confined dogs & Good coverage & Good coverage & Moderate coverage & Rarely applicable* \\
\hline Owned, roaming dogs & Moderate coverage & Moderate coverage & Good coverage & Good coverage \\
\hline Unowned dogs & Poor coverage & Poor coverage & Good coverage & Good coverage \\
\hline Advantage & Inexpensive & $\begin{array}{l}\text { Owners do not have to } \\
\text { transport dogs }\end{array}$ & $\begin{array}{l}\text { Expensive and requires } \\
\text { trained staff }\end{array}$ & $\begin{array}{l}\text { Easy and targets free } \\
\text { roaming dogs }\end{array}$ \\
\hline Disadvantage & $\begin{array}{c}\text { Low free-roaming dog } \\
\text { coverage }\end{array}$ & $\begin{array}{l}\text { Low free-roaming dog } \\
\text { coverage }\end{array}$ & $\begin{array}{l}\text { Cost and scalability } \\
\text { concerns }\end{array}$ & $\begin{array}{c}\text { Cost, safety, and efficacy } \\
\text { concerns }\end{array}$ \\
\hline
\end{tabular}

*Parenteral vaccination should be the preferred method when the dog can be brought for vaccination by an owner. 
Table 5. Summary of recommendations to promote the safe and effective use of oral rabies vaccine in dogs*

Short-term activities (activities to be accomplished by 2021)

Global health agencies should provide guidance on conducting hand-out vaccination programs for dogs

Global health agencies should provide guidance to policy makers on how to interpret complex safety evaluation studies

Policy makers should be encouraged to evaluate the animal and human health impacts (beneficial and harmful) from use of ORV

as a complement to injectable vaccines in dog vaccination programs

International organizations, such as United Against Rabies, should acknowledge the need, role, and acceptability of ORV to further promote safe and cost-effective ORV of dogs

Vaccination programs should be designed using fit-for-purpose methodology, where appropriate methods (or mixed methods)

and vaccine constructs are chosen based on characteristics of the dog population and capacities of the vaccination staff

International organizations should advocate for the use of tools that assess the role of ORV in mixed-method vaccination campaigns to increase awareness of the benefits of ORV

Medium-term activities (activities to be accomplished by 2023)

OIE should continue its efforts to promote the concept of vaccine regulatory convergence to OIE member countries.

Although OIE and WHO do recognize the need for use of animal vaccines off-label, a prospective approach to validating oral rabies vaccines, like the WHO vaccine pre-qualification process, should be developed to provide more confidence in the use of oral rabies vaccines, both in field-trials and integration into mass parenteral vaccination programs

Prequalification should be a future requirement for any oral rabies vaccine to be used for dogs in projects funded or supervised by the United Against Rabies initiative, thereby creating an incentive for manufacturers to invest into this area.

Benchmark immunogenicity studies and field trials should be conducted in several countries representative of regions where dog-mediated rabies is endemic as they are considered crucial to demonstrate the fitness for purpose of oral rabies vaccination as a supplementary tool.

OIE and PAHO should offer these vaccines through their vaccine bank (OIE) and Revolving Fund (PAHO)

Long-term activities (activities to be accomplished by 2025)

Although licensure can be a long, arduous, and expensive process, manufacturers should continue to seek central licensure for use of their products in dogs.

OIE and WHO should consider developing a global regulatory science agenda for oral rabies vaccines, similar to what is recommended for human vaccines

${ }^{*} \mathrm{OIE}$, World Organisation for Animal Health; ORV, oral rabies vaccination; WHO, World Health Organization; PAHO, Pan American Health Organization

\section{Production Capacity for Oral Rabies Vaccines}

No oral rabies vaccine products that are manufactured at a scale that would meaningfully impact the global or regional burden of dog-mediated rabies are commercially available. A lack of demand from customers (national rabies programs and international funders) and a lack of standard bait flavor, size, and composition for dogs were barriers to large-scale production capacities and implementation of ORV of dogs. In recent years, a near-universal bait flavor has been suggested (egg flavor) and compositions that avoid use of plastics and aluminum foil appear safer when ingested by dogs (68). Armed with this new knowledge, mass production of a standard oral rabies vaccine bait seems only limited by a lack of demand. However, field studies should continue to assess bait uptake by modifying bait flavor, composition, and shape. To increase demand of oral rabies vaccines and support sustainable production capacity, OIE and the Pan American Health Organization (PAHO) should offer prequalified oral rabies vaccines through their Vaccine Bank (OIE) and Revolving Fund (PAHO) $(69,70)$.

\section{Cost of Oral Rabies Vaccines}

With no major production of oral rabies vaccines for dogs currently operationalized, the exact cost of these vaccines remains unclear. Costs are expected to be higher than parenteral vaccines (\$2-\$4 USD per ORV bait compared with $\$ 0.30-\$ 1$ USD per parenteral vac- cine) (46). Despite the relatively high cost per oral vaccine dose, studies have shown that inclusion of ORV as a component of a campaign can increase vaccinator efficiency, leading to overall more cost-effective programs compared with persistent undervaccination that might occur with parenteral-only vaccination methods. Although parenteral vaccination remains the preferred route when the dog is accessible, parenteral vaccination complemented by use of ORV for inaccessible dogs can be a cost-effective approach. International organizations, such as United Against Rabies, should acknowledge the need, role, and acceptability of ORV to further promote safe and cost-effective ORV of dogs.

\section{Role of Oral Rabies Vaccine within a Vaccination Program}

Vaccination methods should specifically target dog populations that are essential to the rabies virus transmission cycle (Table 4). Although vaccination of wellowned, often-confined dogs can be performed easily and at low cost, undervaccination of the susceptible dog population leads to persistent rabies endemicity and poor cost-effectiveness (71). New tools have been developed to evaluate the conditions under which ORV might be a cost-effective complementary tool within a mixed-methods vaccination campaign $(46,72,73)$. Although parenteral vaccination with high-quality rabies vaccines is preferred for populations of dogs that are accessible $(45,74)$, complementary ORV of inaccessible 
dogs increases herd immunity. The OIE-endorsed official program for dog-mediated rabies, the OIE Vaccine Bank, and the PAHO Revolving Fund $(69,70)$ present opportunities to provide vaccination planning tools to recipients and require verification that adequate planning and preparations have been conducted. Donors and operators of vaccine banks should be aware of these tools and work with donation recipients to ensure that campaigns will result in cost-effective interventions. International organizations should advocate for the use of tools that assess the role of ORV in mixedmethod vaccination campaigns to increase awareness of the benefits of ORV

\section{Conclusion}

Although the goal of global elimination of human deaths from dog-mediated rabies by 2030 was just recently established, expanding dog vaccination programs and access to human vaccines over the past century has led to a $98 \%$ reduction in global human rabies deaths (14). The remaining $2 \%$ are indeed the proverbial "last mile," and elimination has proven more difficult because of numerous infrastructural, fiscal, and sociodemographic factors. Although the goal of 2030 will require a comprehensive approach to improve surveillance, human postexposure prophylaxis, dog vaccination and dog population management, and awareness programs, the goal will be more feasible if all tools at our disposal are fully used (Table 5). Perhaps the most underused of all tools in the fight against rabies is ORV of dogs. ORV has a vital role as a complementary tool in the global elimination of dog-mediated human rabies deaths, and specific recommended activities should be pursued urgently to promote safe and cost-effective use of ORV.

\section{About the Author}

Dr. Wallace is a veterinary epidemiologist with the Poxvirus and Rabies Branch, Division of HighConsequence Pathogens and Pathology, US Centers for Disease Control and Prevention, National Center for Emerging and Zoonotic Infectious Diseases, and director of CDC's OIE Reference Laboratory for Rabies and leads rabies research and capacity building projects in numerous countries. He has participated in the vaccination of hundreds of thousands of dogs across various settings, methods, and logistical capacities and uses these experiences to develop more effective methods of scalable dog vaccination programs.

\section{References}

1. World Health Organization. Ten years in public health, 2007-2017. Geneva: The Organization; 2017.
2. World Health Organization. Global programme to eliminate lymphatic filariasis: progress report, 2016. Wkly Epidemiol Rec. 2017;92:594-607.

3. Greene SA, Ahmed J, Datta SD, Burns CC, Quddus A, Vertefeuille JF, et al. Progress toward polio eradicationworldwide, January 2017-March 2019. MMWR Morb Mortal Wkly Rep. 2019;68:458-62. https:// doi.org/10.15585/mmwr. mm6820a3

4. The Lancet. Guinea worm disease eradication: a moving target. Lancet. 2019;393:1261. https://doi.org/10.1016/ S0140-6736(19)30738-X

5. Njeumi F, Taylor W, Diallo A, Miyagishima K, Pastoret PP, Vallat $\mathrm{B}$, et al. The long journey: a brief review of the eradication of rinderpest. Rev Sci Tech. 2012;31:729-46. https://doi.org/10.20506/rst.31.3.2157

6. Lambo TA. Eradication of smallpox. N Engl J Med. 1981; 305:224. https:/ / doi.org/10.1056/NEJM198107233050415

7. Minghui R, Stone M, Semedo MH, Nel L. New global strategic plan to eliminate dog-mediated rabies by 2030 . Lancet Glob Health. 2018;6:e828-9. https:/ / doi.org/10.1016/ S2214-109X(18)30302-4

8. Wallace RM, Undurraga EA, Blanton JD, Cleaton J, Franka R. Elimination of dog-mediated human rabies deaths by 2030: needs assessment and alternatives for progress based on dog vaccination. Front Vet Sci. 2017;4:9. https:/ / doi.org/10.3389/ fvets.2017.00009

9. World Health Organization. Zero by 30: the global strategic plan to prevent human deaths from dog-transmitted rabies by 2030 - executive summary. 2018 [cited 2018 Jun 20]. http://www.oie.int/fileadmin/Home/eng/Media_Center/ docs/pdf/Rabies_portal/EN_executiveSummary.pdf

10. World Health Organization. WHO expert consultation on rabies: third report. World Health Organ Tech Rep Ser. 2018;1012:195 [cited 2019 Dec 10]. https:/ / apps.who.int/iris/ handle/10665/272364

11. Rupprecht CE, Barrett J, Briggs D, Cliquet F, Fooks AR, Lumlertdacha B, et al. Can rabies be eradicated? Dev Biol (Basel). 2008;131:95-121.

12. Fooks AR, Banyard AC, Horton DL, Johnson N, McElhinney LM, Jackson AC. Current status of rabies and prospects for elimination. Lancet. 2014;384:1389-99. https:// doi.org/10.1016/S0140-6736(13)62707-5

13. World Health Organization. WHO expert consultation on rabies: second report. World Health Organ Tech Rep Ser. 2013;982:1-139.

14. Hampson K, Coudeville L, Lembo T, Sambo M, Kieffer A, Attlan M, et al.; Global Alliance for Rabies Control Partners for Rabies Prevention. Estimating the global burden of endemic canine rabies. PLoS Negl Trop Dis. 2015;9:e003709. https:/ / doi.org/10.1371/journal.pntd.0003709

15. Shwiff SA, Elser JL, Ernst KH, Shwiff SS, Anderson AM. Cost-benefit analysis of controlling rabies: placing economics at the heart of rabies control to focus political will. Rev Sci Tech. 2018;37:681-9. https://doi.org/10.20506/rst.37.2.2833

16. Müller T, Demetriou P, Moynagh J, Cliquet F, Fooks AR, Conraths FJ, et al. Rabies elimination in Europe - a success story. In: Fooks AR, Müller T, editors. Rabies controltowards sustainable prevention at the source: compendium of the OIE Global Conference on Rabies Control, IncheonSeoul, South Korea, 7-9 Sep 2011. Paris: World Organization for Animal Health; 2012. p. 31-44.

17. Velasco-Villa A, Escobar LE, Sanchez A, Shi M, Streicker DG, Gallardo-Romero NF, et al. Successful strategies implemented towards the elimination of canine rabies in the Western Hemisphere. Antiviral Res. 2017;143:1-12. https:/ / doi.org/ 10.1016/j.antiviral.2017.03.023 
18. Clavijo A, Del Rio Vilas VJ, Mayen FL, Yadon ZE, Beloto AJ, Vigilato MA, et al. Gains and future road map for the elimination of dog-transmitted rabies in the Americas. Am J Trop Med Hyg. 2013;89:1040-2. https://doi.org/10.4269/ ajtmh.13-0229

19. Vigilato MA, Clavijo A, Knobl T, Silva HM, Cosivi O, Schneider MC, et al. Progress towards eliminating canine rabies: policies and perspectives from Latin America and the Caribbean. Philos Trans R Soc Lond B Biol Sci. 2013;368:20120143. https:// doi.org/10.1098/rstb.2012.0143

20. Lapiz SM, Miranda ME, Garcia RG, Daguro LI, Paman MD, Madrinan FP, et al. Implementation of an intersectoral program to eliminate human and canine rabies: the Bohol Rabies Prevention and Elimination Project. PLoS Negl Trop Dis. 2012;6:e1891. https://doi.org/10.1371/journal.pntd.0001891

21. Kayali U, Mindekem R, Hutton G, Ndoutamia AG, Zinsstag J. Cost-description of a pilot parenteral vaccination campaign against rabies in dogs in N'Djaména, Chad. Trop Med Int Health. 2006;11:1058-65. https://doi.org/10.1111/ j.1365-3156.2006.01663.x

22. World Health Organization. Mexico is free from human rabies transmitted by dogs. 2019 [cited 2019 Dec 28]. https://www.who.int/news/item/21-12-2019-mexicois-free-from-human-rabies-transmitted-by-dogs

23. Knobel DL, Cleaveland S, Coleman PG, Fèvre EM, Meltzer MI, Miranda ME, et al. Re-evaluating the burden of rabies in Africa and Asia. Bull World Health Organ. 2005;83:360-8.

24. Freuling CM, Hampson K, Selhorst T, Schröder R, Meslin FX, Mettenleiter TC, et al. The elimination of fox rabies from Europe: determinants of success and lessons for the future. Philos Trans R Soc Lond B Biol Sci. 2013;368:20120142. https://doi.org/10.1098/rstb.2012.0142

25. MacInnes CD, Smith SM, Tinline RR, Ayers NR, Bachmann P, Ball DG, et al. Elimination of rabies from red foxes in eastern Ontario. J Wildl Dis. 2001;37:119-32. https:/ / doi.org/10.7589/0090-3558-37.1.119

26. Slate D, Algeo TP, Nelson KM, Chipman RB, Donovan D, Blanton JD, et al. Oral rabies vaccination in north america: opportunities, complexities, and challenges. PLoS Negl Trop Dis. 2009;3:e549. https:// doi.org/10.1371/journal.pntd.0000549

27. Robardet E, Bosnjak D, Englund L, Demetriou P, Martín PR, Cliquet F. Zero endemic cases of wildlife rabies (classical rabies virus, RABV) in the European Union by 2020: an achievable goal. Trop Med Infect Dis. 2019;4:124. https://doi.org/10.3390/tropicalmed4040124

28. Cliquet F, Guiot AL, Aubert M, Robardet E, Rupprecht CE, Meslin FX. Oral vaccination of dogs: a well-studied and undervalued tool for achieving human and dog rabies elimination. Vet Res. 2018;49:61. https:/ / doi.org/10.1186/s13567-018-0554-6

29. De Balogh KK, Wandeler AI, Meslin FX. A dog ecology study in an urban and a semi-rural area of Zambia. Onderstepoort J Vet Res. 1993;60:437-43.

30. Kayali U, Mindekem R, Yémadji N, Vounatsou P, Kaninga Y, Ndoutamia AG, et al. Coverage of pilot parenteral vaccination campaign against canine rabies in N'Djaména, Chad. Bull World Health Organ. 2003;81:739-44.

31. Vigilato MA, Clavijo A, Knobl T, Silva HM, Cosivi O, Schneider MC, et al. Progress towards eliminating canine rabies: policies and perspectives from Latin America and the Caribbean. Philos Trans R Soc Lond B Biol Sci. 2013;368:20120143. https://doi.org/10.1098/rstb.2012.0143

32. Durr S, Mindekem R, Kaninga Y, Doumagoum Moto D, Meltzer MI, Vounatsou P, et al. Effectiveness of dog rabies vaccination programmes: comparison of owner-charged and free vaccination campaigns. Epidemiol Infect. 2009;137:155867. https://doi.org/10.1017/S0950268809002386
33. Kitala P, McDermott J, Kyule M, Gathuma J, Perry B, Wandeler A. Dog ecology and demography information to support the planning of rabies control in Machakos District, Kenya. Acta Trop. 2001;78:217-30. https:/ / doi.org/10.1016/ S0001-706X(01)00082-1

34. Kongkaew W, Coleman P, Pfeiffer DU, Antarasena C, Thiptara A. Vaccination coverage and epidemiological parameters of the owned-dog population in Thungsong District, Thailand. Prev Vet Med. 2004;65:105-15. https://doi.org/10.1016/j.prevetmed.2004.05.009

35. Dzikwi AA, Ibrahim AS, Umoh JU. Knowledge, attitude and practice about rabies among children receiving formal and informal education in Samaru, Zaria, Nigeria. Glob J Health Sci. 2012;4:132-9. https:/ / doi.org/10.5539/gjhs.v4n5p132

36. Suzuki K, Pereira JA, Frías LA, López R, Mutinelli LE, Pons ER. Rabies-vaccination coverage and profiles of the owneddog population in Santa Cruz de la Sierra, Bolivia. Zoonoses Public Health. 2008;55:177-83. https:// doi.org/10.1111/ j.1863-2378.2008.01114.x

37. van Sittert SJ, Raath J, Akol GW, Miyen JM, Mlahlwa B, Sabeta CT. Rabies in the Eastern Cape Province of South Africa - where are we going wrong? J S Afr Vet Assoc. 2010;81:207-15. https://doi.org/10.4102/jsava.v81i4.149

38. Cleaveland S, Kaare M, Tiringa P, Mlengeya T, Barrat J. A dog rabies vaccination campaign in rural Africa: impact on the incidence of dog rabies and human dog-bite injuries. Vaccine. 2003;21:1965-73. https:/ / doi.org/10.1016/ S0264-410X(02)00778-8

39. Lembo T, Hampson K, Kaare MT, Ernest E, Knobel D, Kazwala RR, et al. The feasibility of canine rabies elimination in Africa: dispelling doubts with data. PLoS Negl Trop Dis. 2010;4:e626. https://doi.org/10.1371/journal.pntd.0000626

40. Adrien J, Georges Y, Augustin PD, Monroe B, Gibson AD, Fenelon N, et al.; Haiti-Rabies Field Response Team. A multipartner response to prevent a binational rabies outbreakAnse-à-Pitre, Haiti, 2019. MMWR Morb Mortal Wkly Rep. 2019;68:707-9. https:/ / doi.org/10.15585/mmwr.mm6832a6

41. Gibson AD, Ohal P, Shervell K, Handel IG, Bronsvoort BM, Mellanby RJ, et al. Vaccinate-assess-move method of mass canine rabies vaccination utilising mobile technology data collection in Ranchi, India. BMC Infect Dis. 2015;15:589. https://doi.org/10.1186/s12879-015-1320-2

42. Gibson AD, Yale G, Vos A, Corfmat J, Airikkala-Otter I, King A, et al. Oral bait handout as a method to access roaming dogs for rabies vaccination in Goa, India: a proof of principle study. Vaccine X. 2019;1:100015. https:/ / doi.org/10.1016/j.jvacx.2019.100015

43. Purwo Suseno P, Rysava K, Brum E, De Balogh K, Ketut Diarmita I, Fakhri Husein W, et al. Lessons for rabies control and elimination programmes: a decade of One Health experience from Bali, Indonesia. Rev Sci Tech. 2019;38:21324. https://doi.org/10.20506/rst.38.1.2954

44. Gibson AD, Wallace RM, Rahman A, Bharti OK, Isloor S, Lohr F, et al. Reviewing solutions of scale for canine rabies elimination in India. Trop Med Infect Dis. 2020;5:47. https://doi.org/10.3390/tropicalmed5010047

45. Smith TG, Millien M, Vos A, Fracciterne FA, Crowdis K, Chirodea $\mathrm{C}$, et al. Evaluation of immune responses in dogs to oral rabies vaccine under field conditions. Vaccine. 2019;37:4743-9. https://doi.org/10.1016/j.vaccine.2017.09.096

46. Wallace RM, Undurraga EA, Gibson A, Boone J, Pieracci EG, Gamble L, et al. Estimating the effectiveness of vaccine programs in dog populations. Epidemiol Infect. 2019;147:e247. https:// doi.org/10.1017/S0950268819001158

47. Ben Youssef S, Matter HC, Schumacher CL, Kharmachi H, Jemli J, Mrabet L, et al. Field evaluation of a dog owner, 
participation-based, bait delivery system for the oral immunization of dogs against rabies in Tunisia. Am J Trop Med Hyg. 1998;58:835-45. https:// doi.org/10.4269/ ajtmh.1998.58.835

48. Matter HC, Kharmachi H, Haddad N, Ben Youssef S, Sghaier C, Ben Khelifa R, et al. Test of three bait types for oral immunization of dogs against rabies in Tunisia. Am J Trop Med Hyg. 1995;52:489-95. https:// doi.org/10.4269/ ajtmh.1995.52.489

49. World Health Organization. Report of WHO consultation on oral immunization of dogs against rabies. Geneva: The Organization; 1988 [cited 2019 Dec 10]. https:/ / apps.who. int/iris/handle/10665/58694

50. World Health Organization. Report of WHO consultation on requirements and criteria for field trials on oral rabies vaccination of dogs and wild carnivores. Geneva: The Organization; 1989 [cited 2019 Dec 10]. https:/ / apps.who. int/iris/handle/10665/58394

51. World Health Organization. Oral vaccination of dogs against rabies - guidance for research on oral rabies vaccines and field application of oral vaccination of dogs against rabies. Geneva, The Organization; 2007 [cited 2019 Dec 10]. https://apps.who.int/iris/handle/10665/331036

52. World Organization for Animal Health. Rabies (infection with rabies virus and other lyssaviruses) [chapter 3.1.17]. In: Manual of Diagnostic Tests and Vaccines for Terrestrial Animals. Meslin F-X, editor. Paris: World Organization for Animal Health; 2018. p. 35 [cited 2019 Dec 10]. https://apps.who.int/iris/handle/10665/331036

53. Cliquet F, Guiot AL, Aubert M, Robardet E, Rupprecht CE, Meslin FX. Correction to: Oral vaccination of dogs: a wellstudied and undervalued tool for achieving human and dog rabies elimination. Vet Res (Faisalabad). 2018;49:84. https:/ / doi.org/10.1186/s13567-018-0579-x

54. Fu R, Altamirano J, Sarnquist CC, Maldonado YA, Andrews JR. Assessing the risk of vaccine-derived outbreaks after reintroduction of oral poliovirus vaccine in postcessation settings. Clin Infect Dis. 2018;67(suppl_1):S26-34. https://doi.org/10.1093/cid/ciy605

55. Medaglia ML, Pessoa LC, Sales ER, Freitas TR, Damaso CR. Spread of cantagalo virus to northern Brazil. Emerg Infect Dis. 2009;15:1142-3. https:// doi.org/10.3201/eid1507.081702

56. Rupprecht CE, Blass L, Smith K, Orciari LA, Niezgoda M, Whitfield SG, et al. Human infection due to recombinant vaccinia-rabies glycoprotein virus. $\mathrm{N}$ Engl J Med. 2001;345:582-6. https:/ / doi.org/10.1056/NEJMoa010560

57. Centers for Disease Control and Prevention (CDC). Human vaccinia infection after contact with a raccoon rabies vaccine bait-Pennsylvania, 2009. MMWR Morb Mortal Wkly Rep. 2009;58:1204-7.

58. Müller T, Bätza HJ, Beckert A, Bunzenthal C, Cox JH, Freuling CM, et al. Analysis of vaccine-virus-associated rabies cases in red foxes (Vulpes vulpes) after oral rabies vaccination campaigns in Germany and Austria. Arch Virol. 2009;154:1081-91. https://doi.org/10.1007/s00705-009-0408-7

59. Hostnik P, Picard-Meyer E, Rihtarič D, Toplak I, Cliquet F. Vaccine-induced rabies in a red fox (Vulpes vulpes): isolation of vaccine virus in brain tissue and salivary glands. J Wildl Dis. 2014;50:397-401. https:// doi.org/10.7589/2013-07-183

60. Vuta V, Picard-Meyer E, Robardet E, Barboi G, Motiu R, Barbuceanu F, et al. Vaccine-induced rabies case in a cow (Bos taurus): Molecular characterisation of vaccine strain in brain tissue. Vaccine. 2016;34:5021-5. https://doi.org/ 10.1016/j.vaccine.2016.08.013

61. Wandeler AI, Capt S, Kappeler A, Hauser R. Oral immunization of wildlife against rabies: concept and first field experiments. Rev Infect Dis. 1988;10(Suppl 4):S649-53. https://doi.org/10.1093/clinids/10.Supplement_4.S649

62. Fehlner-Gardiner C, Nadin-Davis S, Armstrong J, Muldoon F, Bachmann P, Wandeler A. Era vaccine-derived cases of rabies in wildlife and domestic animals in Ontario, Canada, 1989-2004. J Wildl Dis. 2008;44:71-85. https:/ / doi.org/10.7589/0090-3558-44.1.71

63. Pfaff F, Müller T, Freuling CM, Fehlner-Gardiner C, Nadin-Davis S, Robardet E, et al. In-depth genome analyses of viruses from vaccine-derived rabies cases and corresponding live-attenuated oral rabies vaccines. Vaccine. 2019;37:4758-65. https://doi.org/10.1016/j.vaccine.2018.01.083

64. Electronic Code of Federal Regulations. Title 9, subchapter E, part 113. Standard requirements, subjgrp 74: live virus vaccines. 2007 [cited 2019 Dec 10]. https:/ / www.ecfr.gov/ cgi-bin/text-idx?tpl=/ecfrbrowse/Title09/9cfrv1_02.tpl

65. European Directorate for the Quality of Medicines. Rabies vaccine (live, oral) for foxes and raccoon dogs. Strasbourg (France): European Council; 2014. p. 1011-2.

66. Head JR, Vos A, Blanton J, Müller T, Chipman R, Pieracci EG, et al. Environmental distribution of certain modified live-virus vaccines with a high safety profile presents a low-risk, high-reward to control zoonotic diseases. Sci Rep. 2019;9:6783. https://doi.org/10.1038/ s41598-019-42714-9

67. Dellepiane N, Wood D. Twenty-five years of the WHO vaccines prequalification programme (1987-2012): lessons learned and future perspectives. Vaccine. 2015;33:52-61. https://doi.org/10.1016/j.vaccine.2013.11.066

68. Gibson AD, Mazeri S, Yale G, Desai S, Naik V, Corfmat J, et al. Development of a non-meat-based, mass producible and effective bait for oral vaccination of dogs against rabies in Goa State, India. Trop Med Infect Dis. 2019;4:118. https://doi.org/10.3390/tropicalmed4030118

69. World Organization for Animal Health. OIE policy paper on vaccine banks. Paris: World Organization for Animal Health; 2018. p. 16 [cited 2019 Dec 10]. https:/ / www.oie.int/fileadmin/Home/eng/Links/docs/pdf/Policy-Paper-VB-finalEN_Oct-2018_01.pdf

70. Mace J, Renaudin S, Dieuzy-Labaye I, Dehove A. Vaccine banks for controlling dog-mediated rabies. Rev Sci Tech. 2018;37:511-8. https://doi.org/10.20506/rst.37.2.2819

71. Jeon S, Cleaton J, Meltzer MI, Kahn EB, Pieracci EG, Blanton JD, et al. Determining the post-elimination level of vaccination needed to prevent re-establishment of dog rabies. PLoS Negl Trop Dis. 2019;13:e0007869. https://doi.org/10.1371/ journal.pntd.0007869

72. Anderson A, Kotzé J, Shwiff SA, Hatch B, Slootmaker C, Conan A, et al. A bioeconomic model for the optimization of local canine rabies control. PLoS Negl Trop Dis. 2019;13:e0007377. https://doi.org/10.1371/journal. pntd.0007377

73. Borse RH, Atkins CY, Gambhir M, Undurraga EA, Blanton JD, Kahn EB, et al. Cost-effectiveness of dog rabies vaccination programs in East Africa. PLoS Negl Trop Dis. 2018;12:e006490. https://doi.org/10.1371/journal. pntd.0006490

74. Darkaoui S, Cliquet F, Wasniewski M, Robardet E, Aboulfidaa N, Bouslikhane $\mathrm{M}$, et al. A century spent combating rabies in Morocco (1911-2015): how much longer? Front Vet Sci. 2017;4:78. https://doi.org/10.3389/fvets.2017.00078

Address for correspondence: Ryan M. Wallace, Centers for Disease Control and Prevention, 1600 Clifton Rd NE, Mailstop E-84, Atlanta, GA 30329-4027, USA; email: euk5@cdc.gov 